\title{
Interpretação estatística dos processos de evolução e o funcionamento dos arquivos audiovisuais
}

\author{
Nuno Miguel Epifânio \\ Departamento de História, Universidade de Évora - UE, Portugal
}

ARTIGO / ARTICLE

\begin{abstract}
Resumo
O artigo estabelece uma contextualização das condições de funcionamento dos Arquivos Audiovisuais, recorrendo para o efeito à interpretação dos resultados obtidos no estudo de amostragem quantitativa. O referido estudo envolveu 43 Instituições de natureza e dimensão diferenciada, de âmbito nacional e externo, desde a inquirição de órgãos de comunicação a entidades de cariz cultural. A análise do objeto de estudo constatou uma variedade de linhas orientadoras na gestão de preservação da informação assim como caraterizou intrinsecamente a tipologia dos acervos documentais de cada arquivo. A recolha dos dados permitiu desta forma construir uma visão geral sobre o modelo de funcionamento de cada organização inquirida no referido estudo.
\end{abstract}

Palavras-chave

Arquivos audiovisuais ; Amostragem qantitativa ; Recolha de dados ; Gestão da informação ; Preservação da informação

\section{Statistical interpretation of the process of evolution and functioning of Audiovisual Archives}

Abstract

The article provides a type of the operating conditions of audiovisual archives, using for this purpose the interpretation of the results obtained in the study of quantitative sampling. The study involved 43 institutions of different nature of dimension since the national and foreign organizations, from of the questions answered by services of communication and of cultural institutions. The analysis of the object of study found a variety of guidelines on the management of information preservation, as featured the typology of records collections of each file. The data collection thus allowed building an overview of the operating model of each organization surveyed in this study.

Keywords

Audiovisual archives ; Quantitative sampling ; Data collection ; Information management ; Preservation of information

\section{Introdução}

O presente artigo analisa um estudo de natureza quantitativa que foca o estado geral dos Arquivos Audiovisuais, sendo analisada particularmente a politica adotada em cada Instituição relativamente aos procedimentos de gestão e preservação da informação.

Nessa perspetiva foi realizado um inquérito no qual consta uma amostra das Organizações que dispõem de Arquivos Audiovisuais, estando incluídos dados relativos a Instituições de comunicação social e de entidades públicas.

O estudo é de natureza quantitativa, visando a compreensão das condições de preservação do acervo documental gerado por estas Organizações no contexto nacional. Pretende-se assim ter um conhecimento do papel e da 
evolução das unidades de arquivo, designadamente a nível técnico e dos recursos humanos constituídos nas referidas Instituições.

A sociedade em geral não tem um conhecimento preciso da sua importância nomeadamente, na difusão e salvaguarda da informação.

Estas Instituições nunca tiveram um papel visível, estando confinadas a espaço hermético nas Instituições onde estão integradas. O mesmo quadro reflete-se a nível académico, não se verificando com relativa frequência estudos sobre os Arquivos Audiovisuais no contexto nacional.

O desinteresse sobre as funções e o grau de evolução destas Instituições é notório, não sendo uma matéria de interesse em torno das Ciências da Informação.

A nossa intenção foi contrariar essa tendência, de isolamento e de esquecimento, que assola estas Organizações.

Nessa conformidade, além da análise estatística são descritos os meios técnicos de preservação e os formatos de registo de informação disponíveis em cada unidade de arquivo das organizações inquiridas.

O universo da amostra do estudo é bastante heterogêneo, abarcando a caracterização de arquivos, dispondo os vários formatos audiovisuais oriundos de organismos de comunicação sociais e, de Instituições Públicas (arquivos, bibliotecas e museus).

Houve também a recetividade de Instituições estrangeiros em responder ao inquérito, nomeadamente os Serviços de Arquivo da BBC, Rádio e Televisão Pública da República da Irlanda e do Arquivo Nacional da Croácia.

Os dados fornecidos por estas Organizações tornaram-se num instrumento bastante útil em comparação com os procedimentos que tem sido instituídos na preservação e gestão da informação pelas unidades de arquivo a nível nacional.

As respostas obtidas proporcionaram uma visão alargada e heterogénea sobre o funcionamento e a tipologia dos suportes documentais arquivados nas entidades representadas na amostra.

Em relação à metodologia utilizada no tratamento da informação procedeu-se numa primeira fase à recolha dos dados sendo transporta para um ficheiro Excel. Posteriormente foi estabelecido o tratamento da informação usando para o efeito, o programa estatístico SPSS. O modelo de inquérito escolhido está estruturado por perguntas semiabertas e de escolha múltipla, o que facilitou o próprio tratamento da informação.

\section{Análise contextual dos Arquivos Audiovisuais em Portugal}

Antes de nos debruçarmos sobre a situação geral dos Arquivos Audiovisuais em Portugal, importa frisar o conceito de Arquivo nesta área.

Não há definições específicas, as organizações internacionais (FIAF ${ }^{1}$ ou a IASA ${ }^{2}$ ), não fornecem uma definição concreta. Esta é variável de autor para autor, sendo conhecido geralmente da opinião pública, como organizações que armazenam e gerem documentos audiovisuais em vários formatos. De fato é uma definição muito sucinta e redutora, um Arquivo Audiovisual é mais do que essa missão atribuída, atualmente é uma entidade com diversas funcionalidades. ${ }^{3}$ Não é somente um espaço recetor de registos sonoros, fílmicos, vídeo e fotográfico.

Estas Instituições têm uma vasta missão, assumindo um elemento preponderantes no seio da organização, desempenhando funções essenciais na gestão e salvaguarda de informação ${ }^{4}$. Além disso, estas ainda assumem um papel cultural e social na defesa do património oral e audiovisual.

A realidade dos arquivos audiovisuais no contexto português está confinada aos principais órgãos de comunicação e instituições culturais que dispõem de meios técnicos e também de serviços autónomos para preservar o material audiovisual.

O quadro de limitação financeira obriga muitas organizações públicas e privadas que albergam documentação audiovisual, a não disporem de condições adequadas para a salvaguarda de registos documentais. 
Só as principais estações de televisão e de rádio estão organizadas com serviços de arquivo estruturados, tendo sido a Rádio Difusão Portuguesa (RDP) a primeira empresa a criar um arquivo histórico.

A maioria das estações de rádio não tem, portanto, um arquivo organizado e, por isso, pressupõem-se que uma quantidade assinalável de gravações armazenadas em diversas estações de rádio, contendo documentação histórica, possa desaparecer por falta de meios técnicos para a sua preservação.

O advento dos canais televisivos por cabo poderá constituir um fator decisivo na afirmação dos serviços de arquivo na área do audiovisual, existindo ainda um longo caminho a percorrer. Entre nós, as estações pioneiras foram a Rádio Televisão Portuguesa (RTP) e a Sociedade Independente de Comunicação (SIC) que já dispõem de serviços de arquivo audiovisual, encontrando-se já equipadas com um sistema digital de arquivo (Digital Storage Archive). Assinala-se também a existência de arquivos institucionais, o caso dos Arquivos de Imagens da Assembleia da República (IAAR) e o Nacional de Imagens em Movimento (ANIM). Este último está integrado na Cinemateca Portuguesa (CP), estando incumbido das funções de depósito legal uma vez que alberga o espólio das obras cinematográficas produzidas em Portugal.

Uma parte considerável de património audiovisual e sonoro encontra-se também noutras instituições privadas e públicas ${ }^{5}$. A informação contida no Guia dos Arquivos Audiovisuais em Portugal permite estabelecer o retrato geral sobre as condições gerais das Instituições, como define o tipo de acervo documental existente.

No inventário realizado constam a presença de organismos públicos/privados que albergam coleções documentais em formato de filme, vídeo, fotografia e sonoro. Muitas destas entidades não dispõem de condições técnicas ideais para à correta preservação do espólio documental.

Relativamente aos organismos públicos, constata-se igualmente a presença de coleções documentais em vários formatos (fílmico vídeo, sonoro e fotográfico). A maioria dessas coleções encontra-se em entidades públicas, tais como: Bibliotecas, Centros de Documentação, em Instituições de Ensino e em Museus.

Geralmente, o conteúdo acervo documental está relacionado com atividade das próprias organizações. À exceção dos Museus, que dispõem sobretudo de coleções em suporte fotográfico alusivo ao quadro temático do espólio existente nas suas instalações.

Ainda na esfera pública, subsiste nas instituições locais, nomeadamente nos Arquivos e Bibliotecas Municipais, registos documentais dos vários formatos audiovisuais, retratando normalmente acontecimentos de interesse local. Porém, devido á escassez de recursos técnicos e humanos o espólio documental existente nesses locais, não é sujeita às condições de organização e de preservação ideais.

No domínio privado subsistem algumas empresas de produção de audiovisual, destacando-se a Panavídeo ou Duvídeo, que dispõem de arquivo próprio.

De acordo com os dados obtidos, não se verifica a existência de outras organizações privadas que comercializem ou arquivem registos sonoros ou fotográficos. O mercado está praticamente concentrado no sector audiovisual, muitas das empresas têm uma ligação direta à produção de programas de televisão, anúncios publicitários e filmes. Podese considerar que os arquivos inerentes a estas organizações têm uma dimensão restrita, albergando apenas 0 acervo documental produzido por estas entidades.

Focando a questão da legislação, esta representa um condicionalismo à sua autonomia, não vigorando legislação específica que regule as funções desenvolvidas.

O regime legal depende na maioria das vezes das prerrogativas do Código de Direito de Autores e Direitos Conexo. Nem o referido código nem a legislação vigente, que regula o setor da comunicação social, oferecem garantias jurídicas na resolução de problemas no âmbito na reprodução e preservação da informação. As disposições do CDADC em relação à propriedade intelectual da obra, em determinadas situações não se adaptam ao contexto funcional dos arquivos audiovisuais. Este instrumento legal está direcionado para a proteção dos direitos de autor e comerciais da propriedade intelectual de uma obra, fornecendo nesse domínio um conjunto de orientações de âmbito generalista para ser utilizado como um elemento de referência nestes serviços. Aliás, nesta matéria, a IASA e a FIAF recomendam a adoção, numa primeira instância, da legislação nacional e, só posteriormente, a de âmbito 
internacional, relativa, por exemplo, ao código de direitos autores, nomeadamente na reprodução e depósito legal dos registos sonoros e de imagens. ${ }^{6}$

\section{Interpretação dos resultados}

A amostra deste estudo é constituída por 43 instituições, metade das quais têm o seu registo constituído unicamente por uma tipologia e, as restantes têm o seu registo constituído por duas ou mais tipologias, conforme se pode observar no seguinte diagrama circular ${ }^{7}$ :

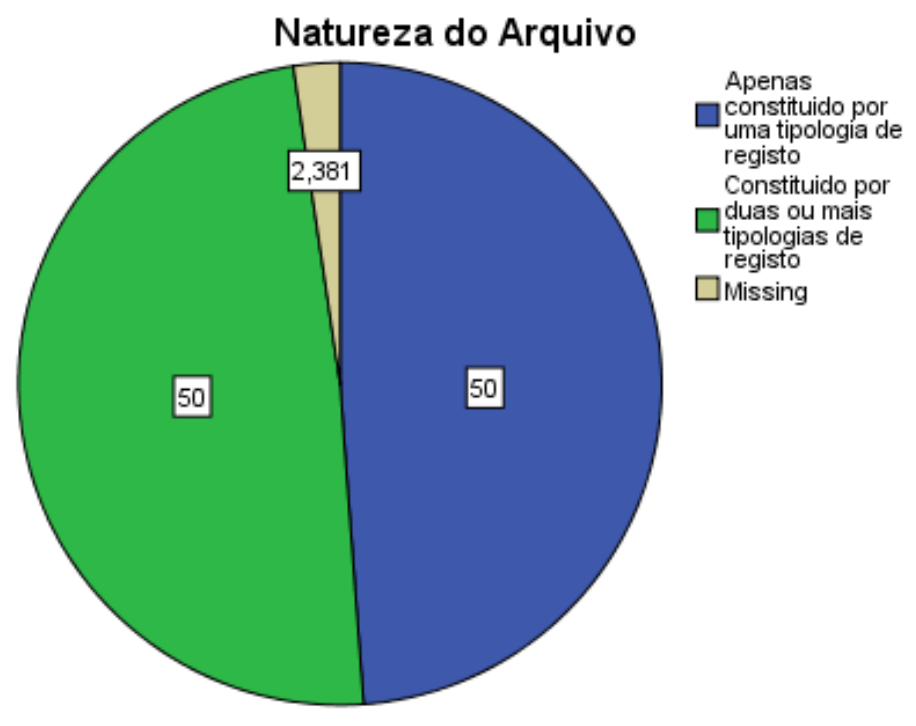

Gráfico 1 - Caraterização da tipologia dos Arquivos

Em relação à tipologia do registo, pode afirmar-se que aproximadamente $64 \%$ das Instituições incluem no seu arquivo registos sonoros e, $55 \%$ possuem no seu arquivo registos audiovisuais e fotográficos.
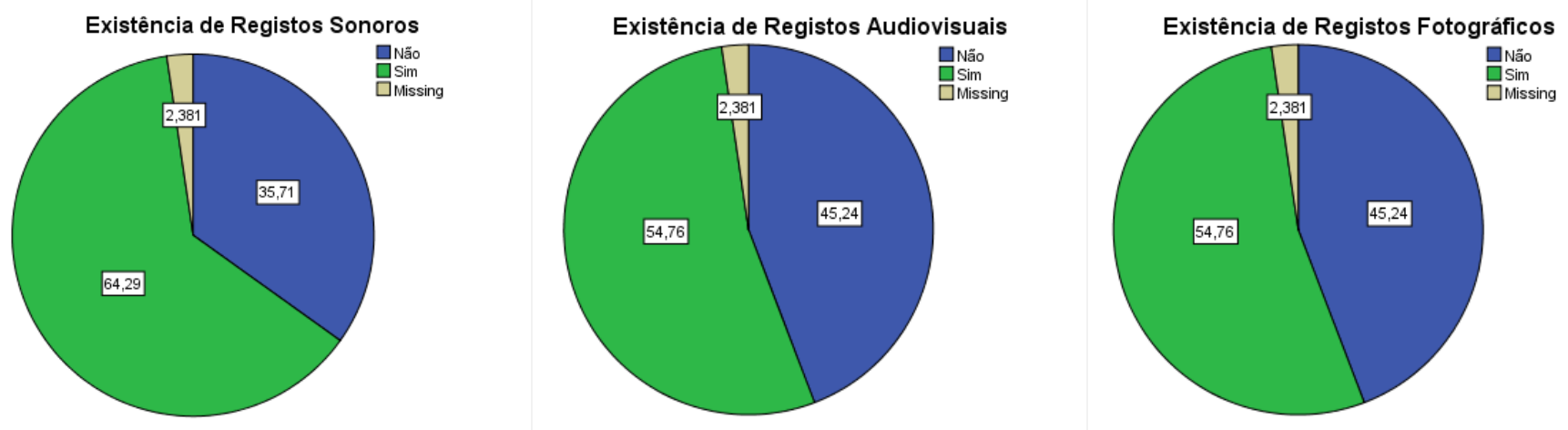

Gráfico 2 - Percentagem da tipologia dos Arquivos Audiovisuais 
A maioria das instituições foi fundada no período compreendido entre 1980 e 1999 (cerca de 42\%) constituindo-se assim, de forma geral, como Instituições fundadas do Século passado, uma vez que apenas $5 \%$ foi fundada no presente século e 19\% no século XIX, como se pode deduzir no gráfico de barras seguinte:

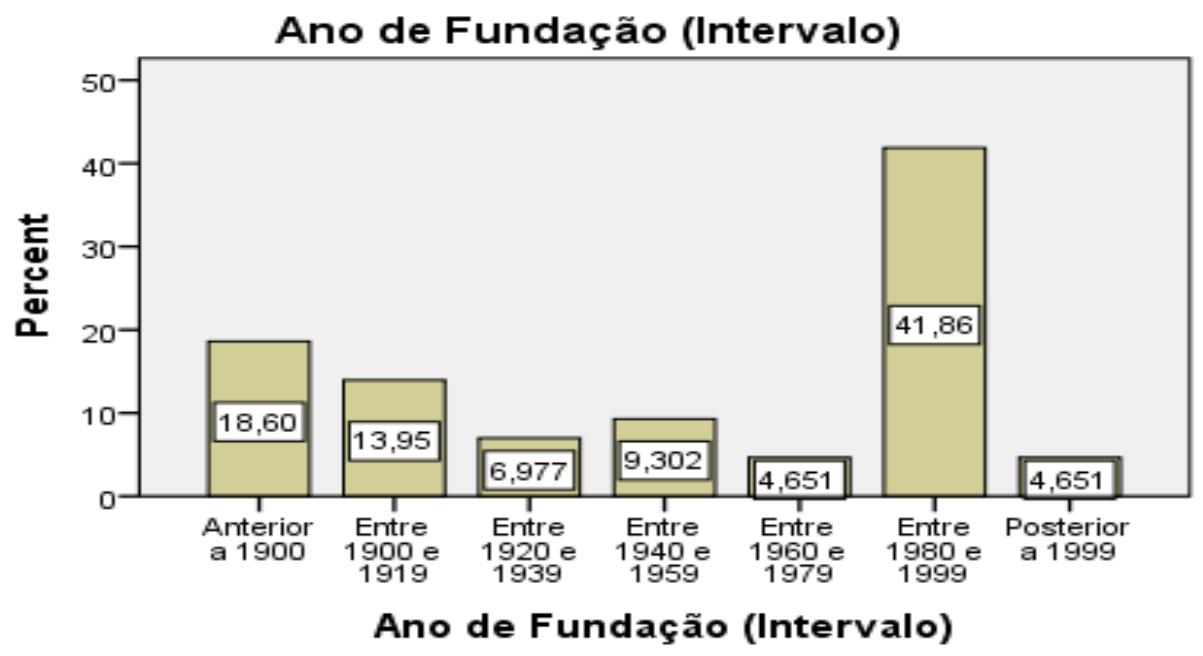

Gráfico 3- Indicação do período de fundação das Instituições

Em relação à natureza das funções desenvolvidas por todas Instituições analisadas, incidem essencialmente na gestão e preservação da informação (cerca de $88 \%$ ). O número poderá variar entre as organizações que apenas custodiam a documentação (cerca de $76 \%$ ) e, aquelas que também integram funções de divulgação da informação (cerca de 66\%).

Em menor grau seguem-se as funções de Tratamento (cerca de 27\%) e Gestão (Classificação e Indexação de Programas) com $24 \%$.
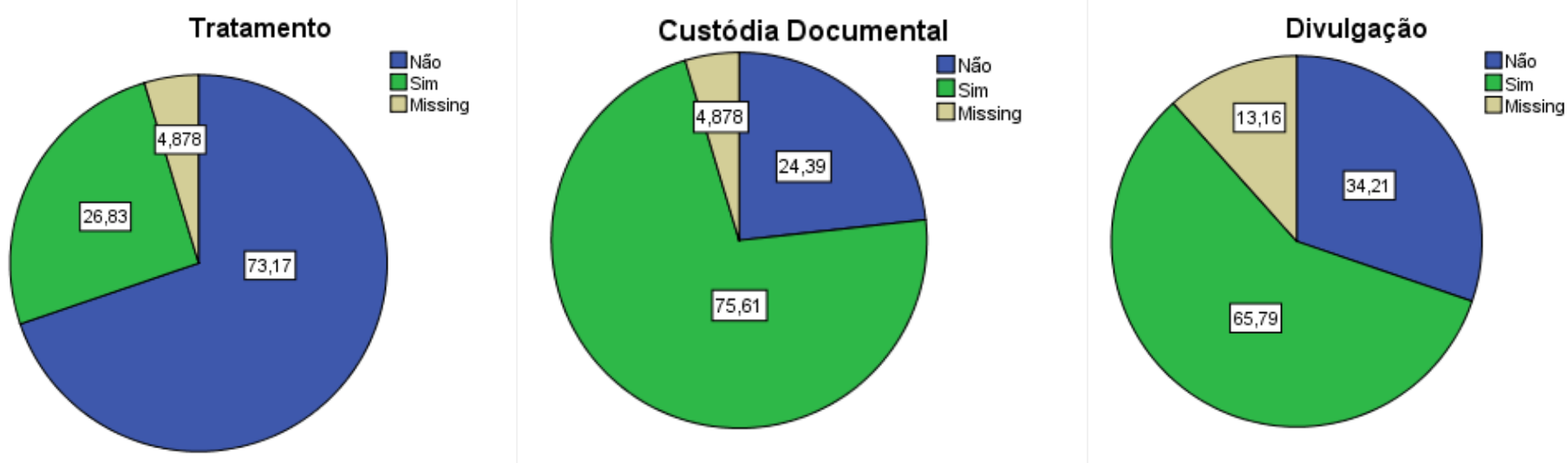
As funções de Organização, Descrição e Classificação de Programas, Comercialização, Restauro do Conteúdo Documental e/ou do Acervo, Conservação do Espólio Documental e Preservação Digital podem, no contexto da amostra, considerar-se como elementos, em virtude do conjunto destas funções não reunir mais de $15 \%$, conforme se pode comprovar no seguinte conjunto de gráficos apresentados:
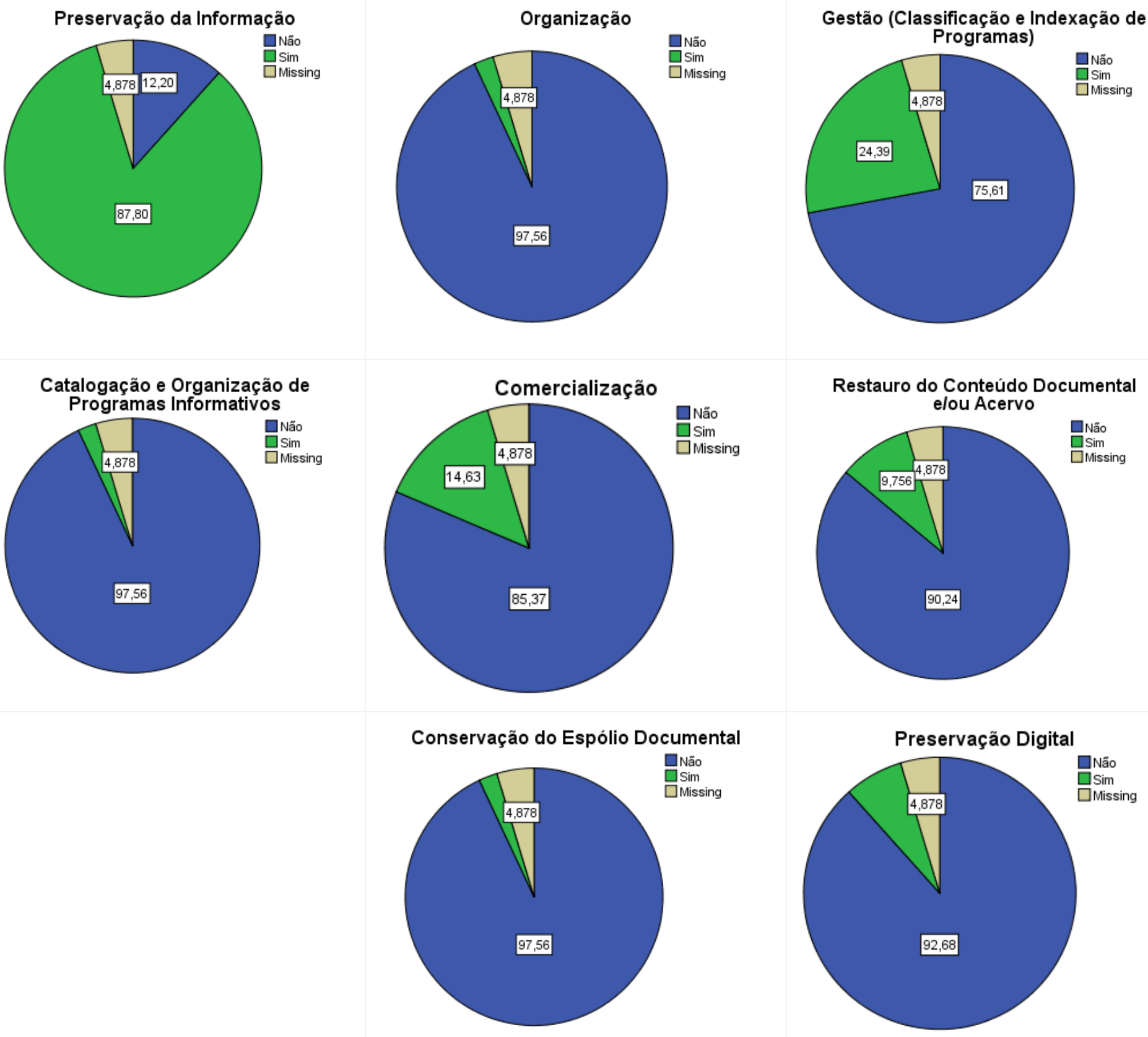

Gráfico 5 - Representação das atividades prestadas pelos Arquivos Audiovisuais inquiridos 
Relativamente ao número de horas gravadas por cada Instituição, um quinto das delas possui um número de horas de registo entre 15000 e 2500, este é o valor com maior frequência do estudo e, metade das Instituições possui 15000 ou mais horas gravadas na sua posse, conforme se pode concluir da observação da tabela de frequências e gráfico de barras seguintes:

\begin{tabular}{|c|c|c|c|c|c|}
\hline \multicolumn{6}{|c|}{$\mathrm{N}^{0}$ total de horas gravadas (intervalo) } \\
\hline & & Frequency & Percent & Valid Percent & $\begin{array}{c}\text { Cumulative } \\
\text { Percent }\end{array}$ \\
\hline \multirow[t]{7}{*}{ Valid } & 0 & 1 & 2,3 & 3,8 & 3,8 \\
\hline & $500-1000$ & 6 & 14,0 & 23,1 & 26,9 \\
\hline & $1000-2000$ & 2 & 4,7 & 7,7 & 34,6 \\
\hline & $2000-5000$ & 4 & 9,3 & 15,4 & 50,0 \\
\hline & $15000-25000$ & 9 & 20,9 & 34,6 & 84,6 \\
\hline & Mais de 25000 & 4 & 9,3 & 15,4 & 100,0 \\
\hline & Total & 26 & 60,5 & 100,0 & \\
\hline Missing & System & 17 & 39,5 & & \\
\hline Total & & 43 & 100,0 & & \\
\hline
\end{tabular}

Tabela 1 Número de total de horas gravadas de cada Instituição

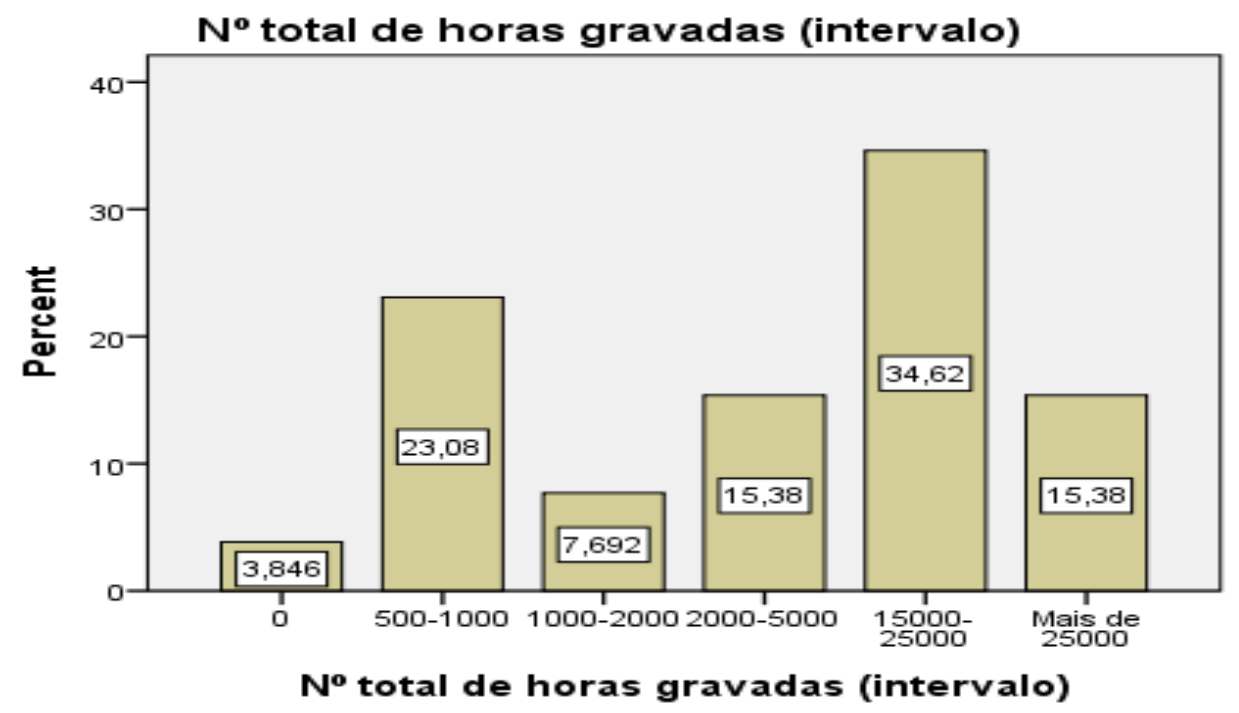

Gráfico 6 - Número de total de horas gravadas 
O tipo e a natureza do conteúdo dos registos arquivados em cada entidade inquirida é, na sua maioria, informativo e documental (cerca de 89\%). Os conteúdos Musicais (cerca de 47\%) e Entretenimentos (37\%) são em menor número. Os dados são confirmados nos seguintes gráficos:
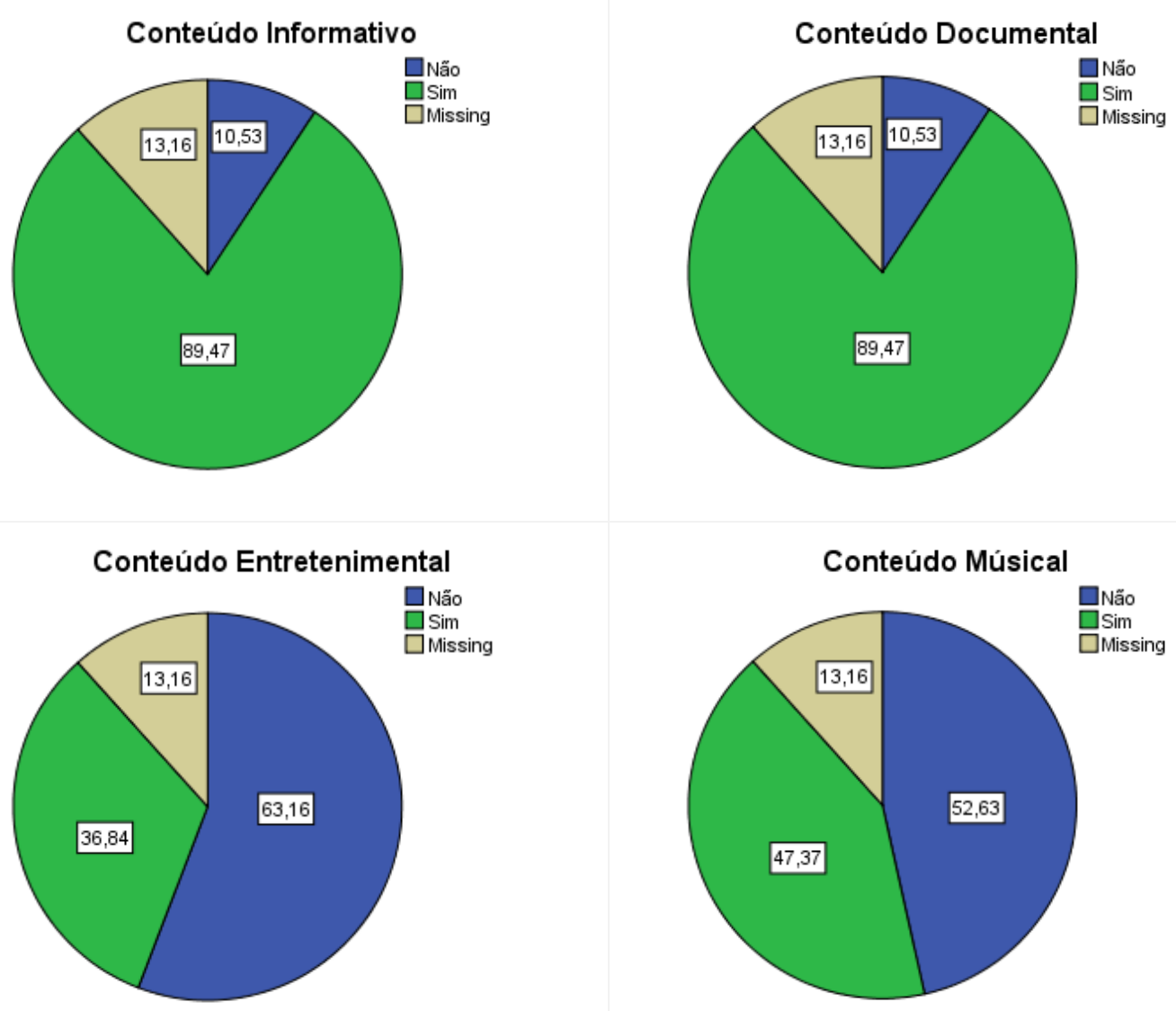

Gráfico 7 - Conteúdo da natureza documental sob custódia nas Instituições 
O período em relação ao Acervo Documental encontra-se identificado no seguinte gráfico de barras:

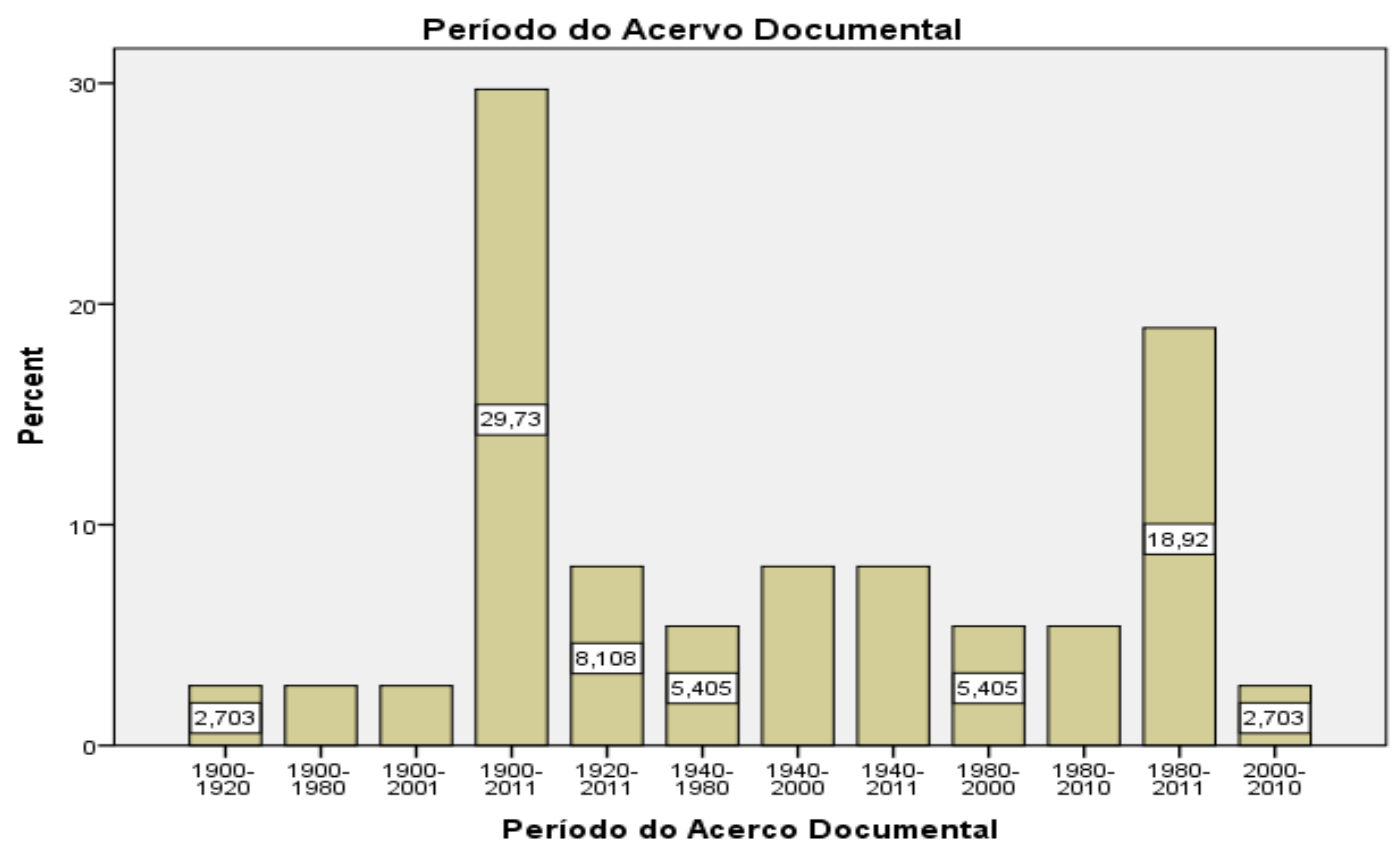

Gráfico 8 - Indicação do Período de Acervo Documental preservado nas organizações

Uma parte significativa das instituições foi constituída nos últimos 30 anos do século XX. Um terço dos arquivos tem sob a sua custódia registos documentais que se reportam desde o início do século passado até atualidade. Além disso, 35\% das unidades de arquivo não dispõem de nenhum instrumento de gestão documental para descrever o acervo documental arquivado.

Foi igualmente analisada a tipologia documental, estando segmentada em duas áreas distintas: sonoro e audiovisual (Filme, Vídeo e Fotografia). No formato sonoro constatou-se que o CD (cerca de 61\%) é o suporte mais utilizado pelas Instituições, seguido dos Ficheiros Digitais (cerca de 59\%). Os suportes, tais como: Cassetes Áudio, Disco de Vinil e Banda Magnética já tiveram o seu apogeu mas estando já em desuso (42\%, 27\% e 24\% respetivamente). Os discos (de acetato e celulose) apresentam um valor residual (percentagens inferiores a 15\%). 

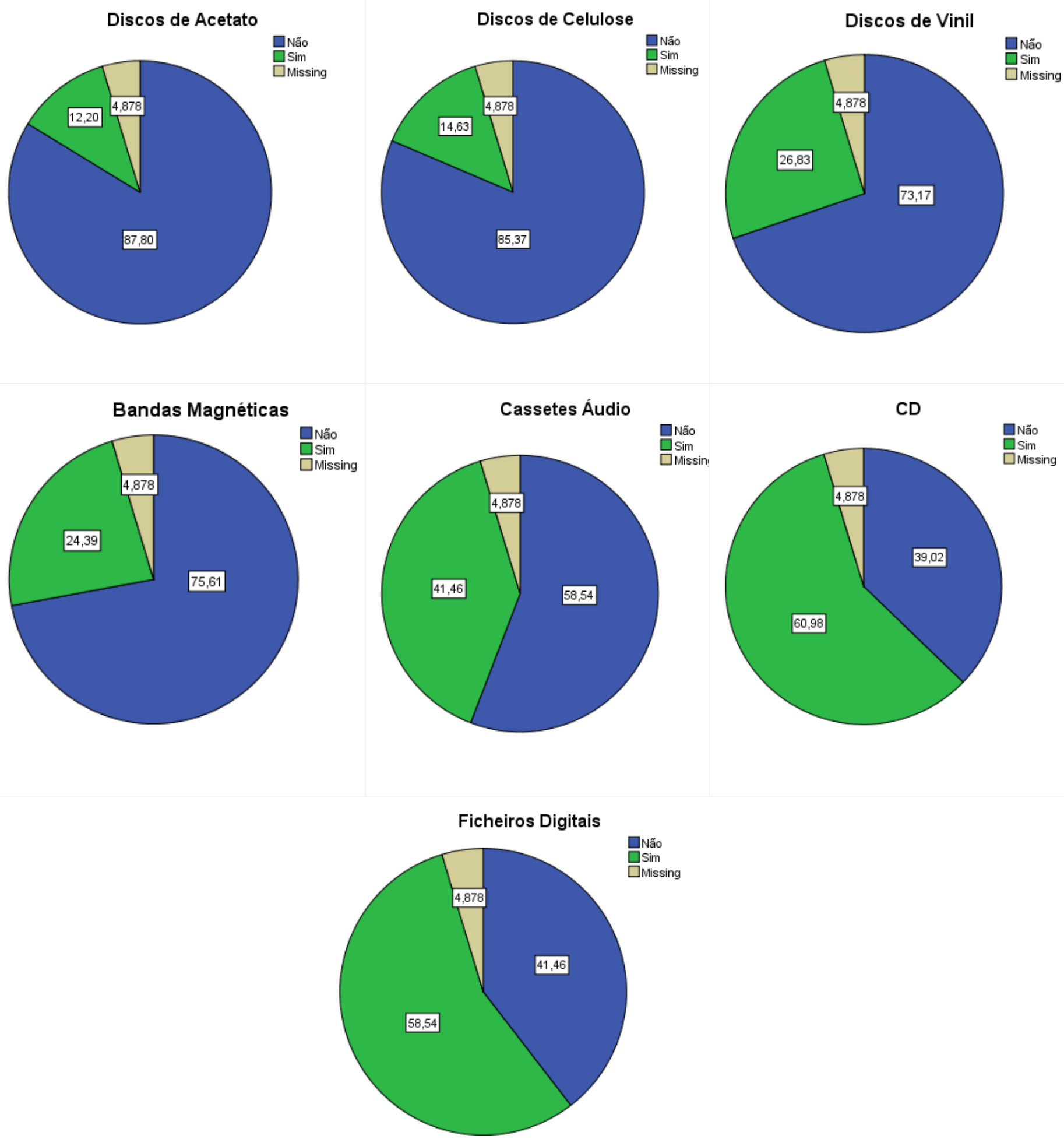

Gráfico 9 - Tipologia dos formatos documentais sonoros 
Em relação ao formato audiovisual, o Filme está distribuído por duas categorias pouco representativas: Nitrato de Celulose e Acetato de Celulose ( $8 \%$ e $12 \%)$.
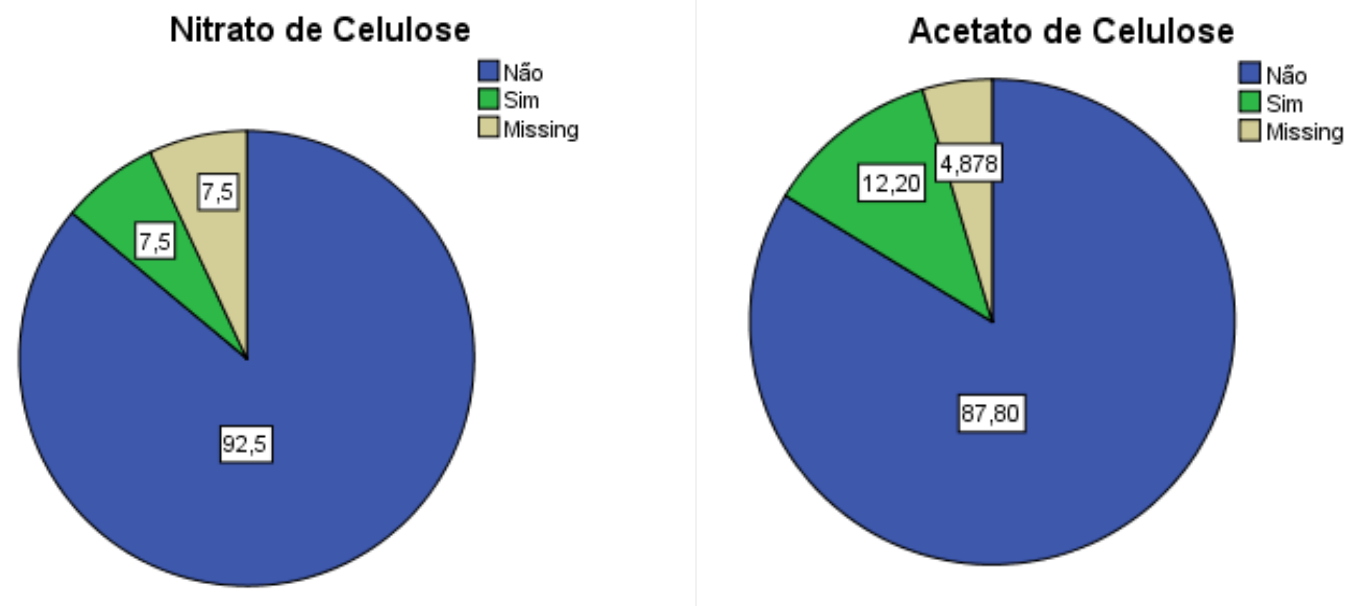

Gráfico 10 - Tipologia dos formatos documentais em acervo fílmico 
Nas Instituições que disponibilizam o formato de vídeo arquivado, observou-se a presença de 5 formatos, conforme se pode constatar nos seguintes gráficos:
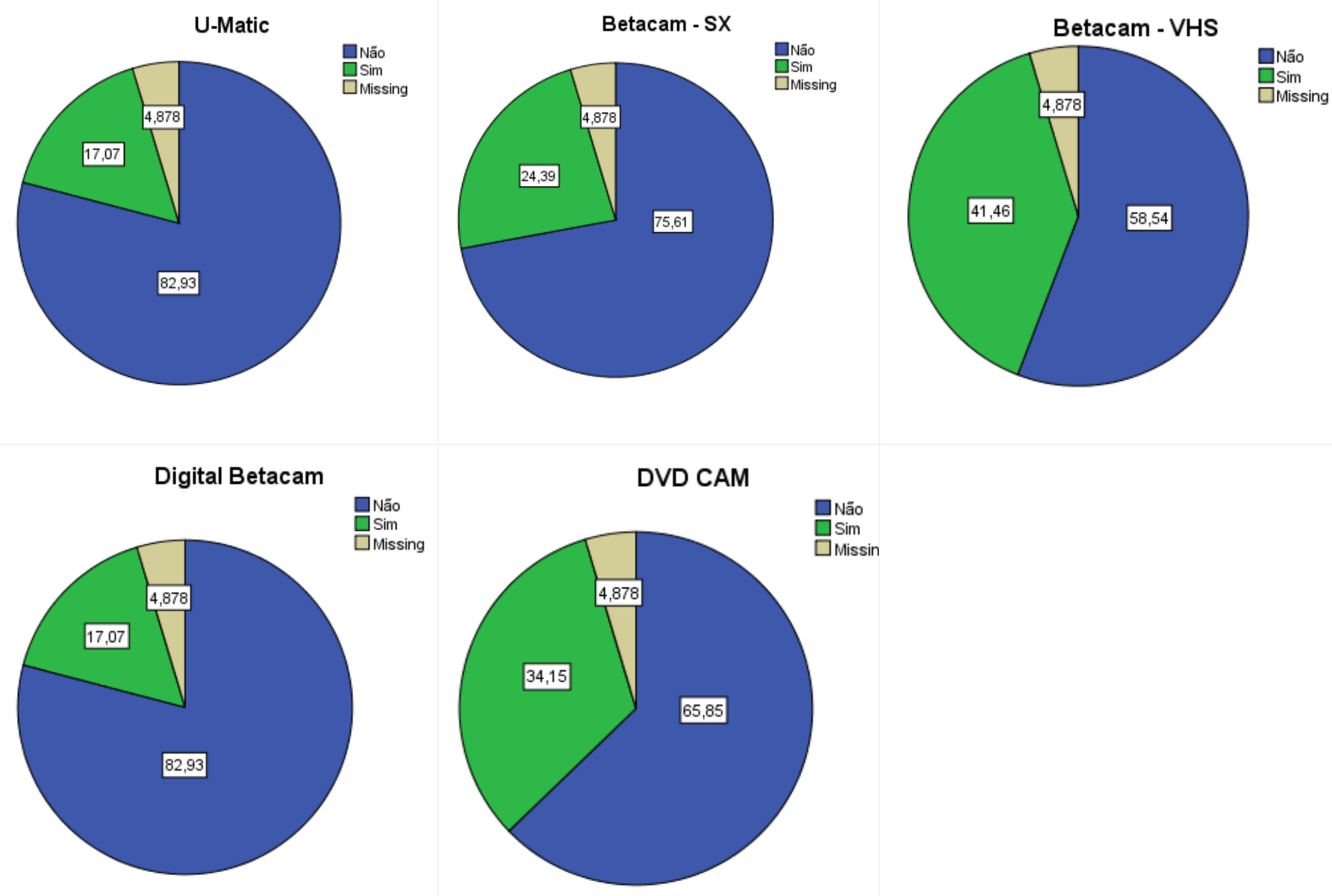

Gráfico 11- Tipologia dos formatos documentais de vídeo

Somente o Betacam -VHS (cerca de 41\%) e o DVD-CAM (cerca de 34\%) são as tipologias de vídeo com maior representação nas unidades de arquivo, enquanto os formatos U-MATIC, Betecam SX e VHS têm um menor peso, fruto de constituírem uma tecnologia já obsoleta e não ser utilizada na gravação. A percentagem das Instituições que preservam o suporte fotográfico é variável, estando repartido por quatro tipologias distintas. 

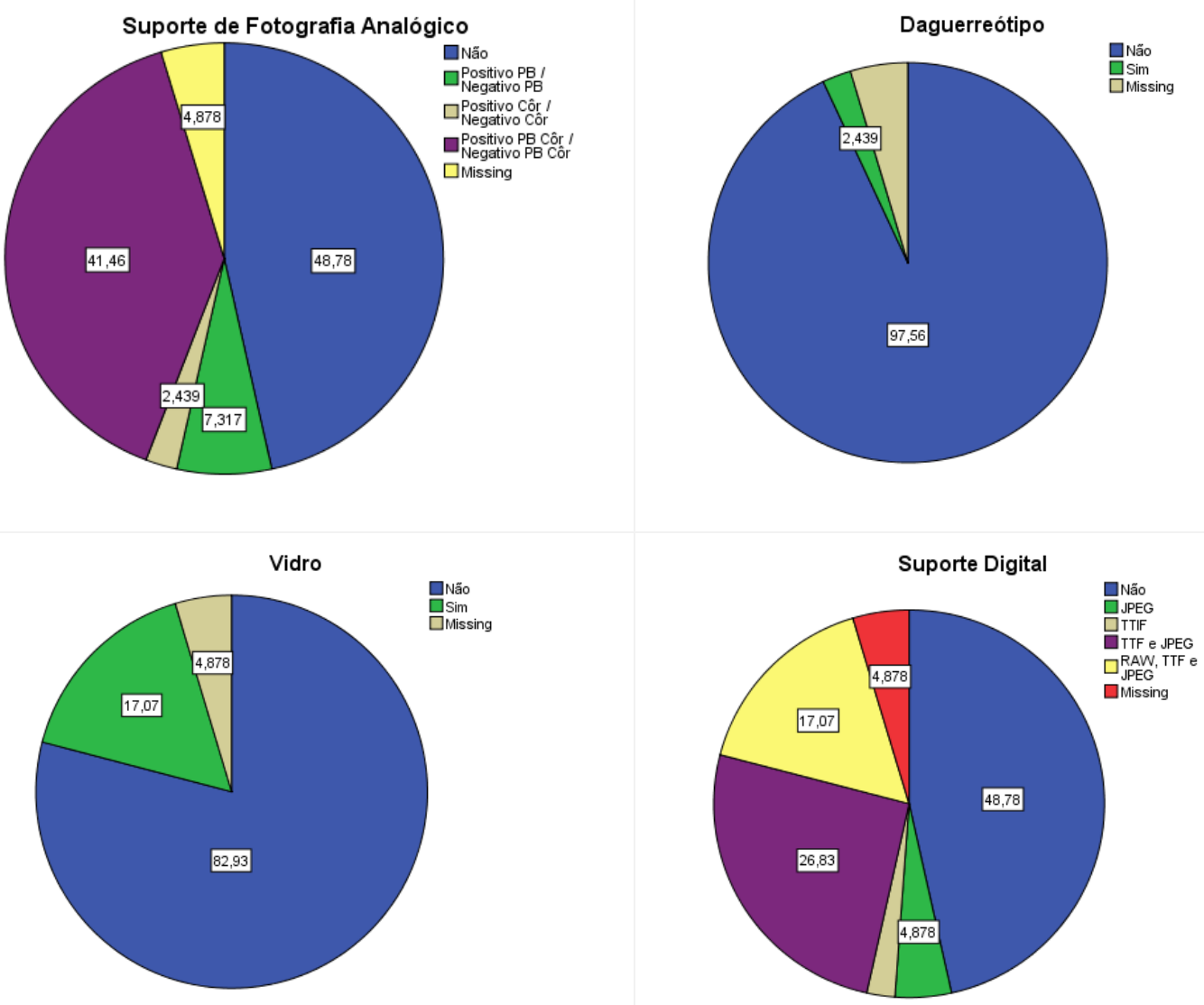

Gráfico 12 - Evolução e especificação dos formatos em suporte fotográfico

De acordo com os gráficos apresentados, os suportes de fotografia em Vidro e Daguerreótipo, estão em claro desuso como demonstram os números. O primeiro de $2,4 \%$ e o segundo $17,07 \%$, enquanto sensivelmente metade das Instituições, 51\%, opta pelo suporte analógico.

Um dos dados a salientar é relativo ao formato digital, apenas $27 \%$ das organizações arquivo de documentos no referido formato. Isto demonstra a importância desta tecnologia na preservação da informação.

É cada vez maior o número de Instituições que recorrem ao formato digital devido à sua capacidade e fiabilidade no armazenamento da informação.

A variável relativa às condições ambientais de preservação da documentação demonstra que 68\% das Instituições inquiridas apresenta instalações com uma temperatura entre os $10 \% / 20^{\circ}$. Por outro lado, $15 \%$ das instalações de arquivos analisados dispõem de uma temperatura ambiente que varia em dois ou mais intervalos de temperatura.

A variabilidade de temperatura é um indicador de que o diferente material arquivado necessita de uma diferente temperatura ambiental para ser preservado.

Da informação obtida, não nos foi possível compreender as condições físicas existentes em cada Instituição. A quantificação dos dados referentes a esta variável está identificada em baixo: 


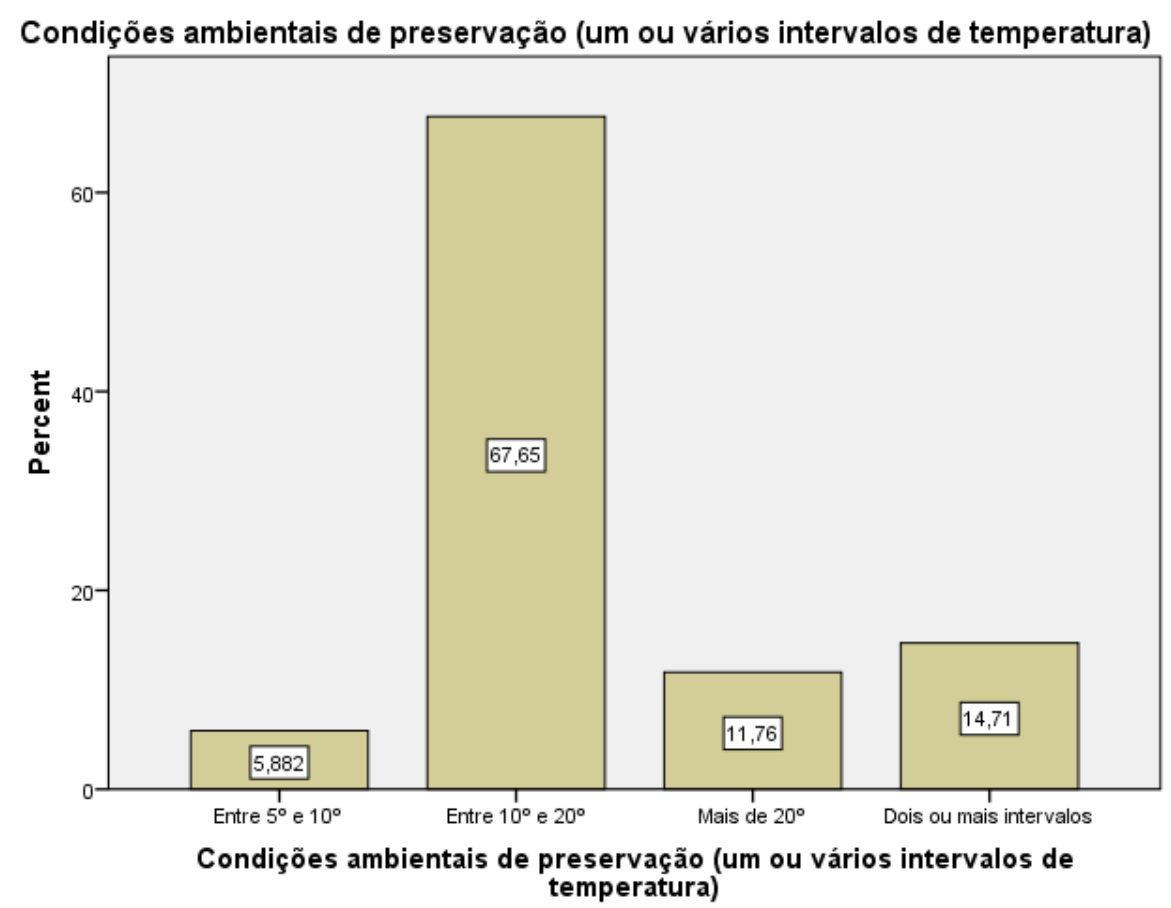

Gráfico 13 - Variabilidade das condições ambientais de preservação em cada instituição

Também foi analisado o modelo de tratamento técnico e preservação da informação, subsistindo nove metodologias diferenciadas implementadas em cada Instituição. A adoção de um software específico constitui o procedimento mais utilizado pelas organizações, em $58 \%$.

Relativamente, ao modelo de tratamento documental, constata-se $41 \%$ das instituições adotam procedimentos na representação da informação, sendo instituído igualmente o princípio da proveniência dos documentos na gestão do acervo documental. Este princípio fundamental em arquivística, independentemente da natureza do arquivo ou serviço de documentação é aplicável em qualquer organização, em virtude de consagrar que qualquer sistema de organização documental deve respeitar sempre a origem e a proveniência dos documentos das entidades produtoras. As metodologias em questão têm uma maior aplicabilidade por parte das Instituições, devido a não terem um impacto de custos elevado, nomeadamente a elaboração de um programa informático de base de dados, assim como o princípio de proveniência que se adapta em geral à realidade do funcionamento das Instituições.

Ao contrário de outras metodologias de preservação e tratamento da informação, como é o caso da migração de dados que representa $31 \%$ das opções usadas pelas Instituições, já que o respetivo procedimento exige tecnologia e software adequado como meios técnicos específicos para reconverter a informação.

Além disso, não se verifica a adoção de um plano de classificação funcional e nem a descrição e catalogação de documentos (ambas com 25\%), isto deve-se á carência de recursos humanos para realizar os referidos procedimentos. 
As restantes modalidades de tratamento técnico são consideradas residuais pois a percentagem de uso é bastante baixa, como se pode constatar no gráfico seguinte:

Recurso a um programa informático de acordo com a norma de Arquivo ISAD(G)

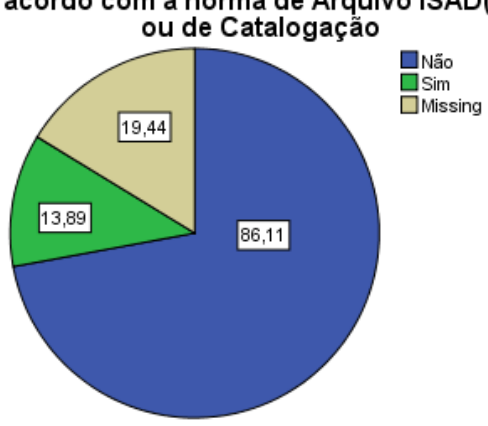

Aplicação do Princípio da Proveniểncia da Organização
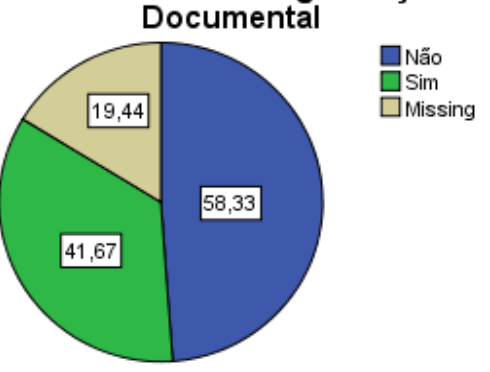

Missing

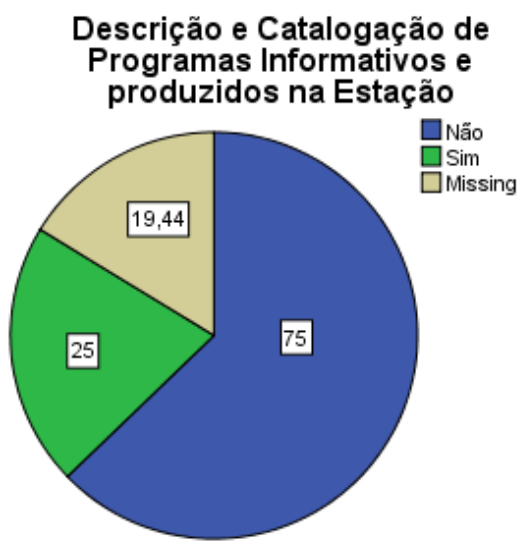

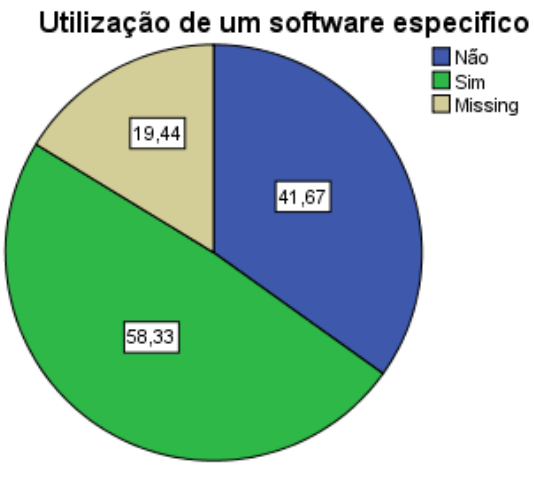
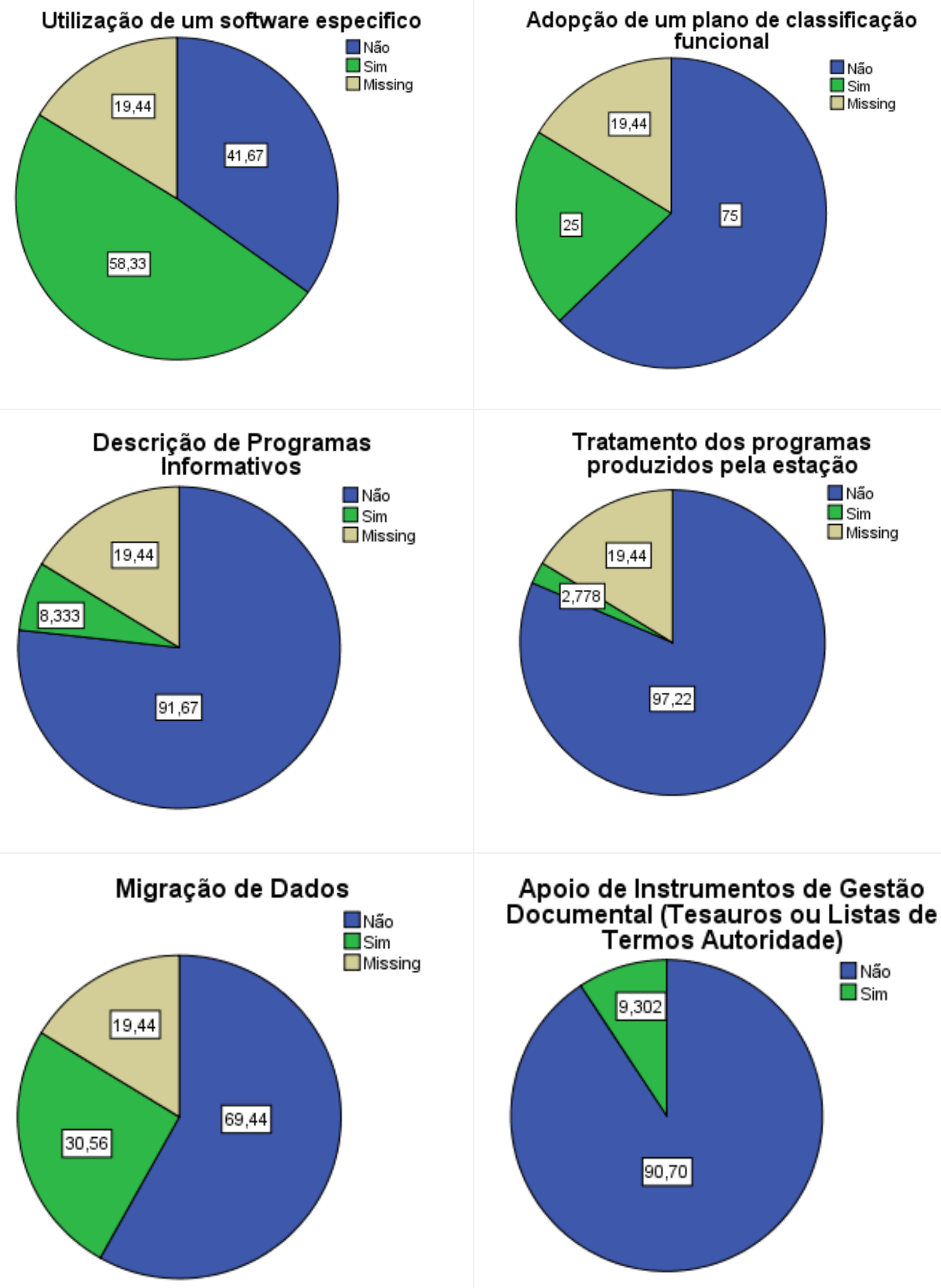
Finalmente, a última questão do inquérito relativo à implementação do Sistema Digital Integrado, só um terço das Instituições procederam à sua implementação (cerca de 27\%). A maior parte delas (cerca de 39\%) preveem proceder à sua implementação em 1 a 2 anos.

De referir que atualmente $9 \%$ das Instituições, não têm data de previsão para a referida implementação, como se pode observar no seguinte gráfico:

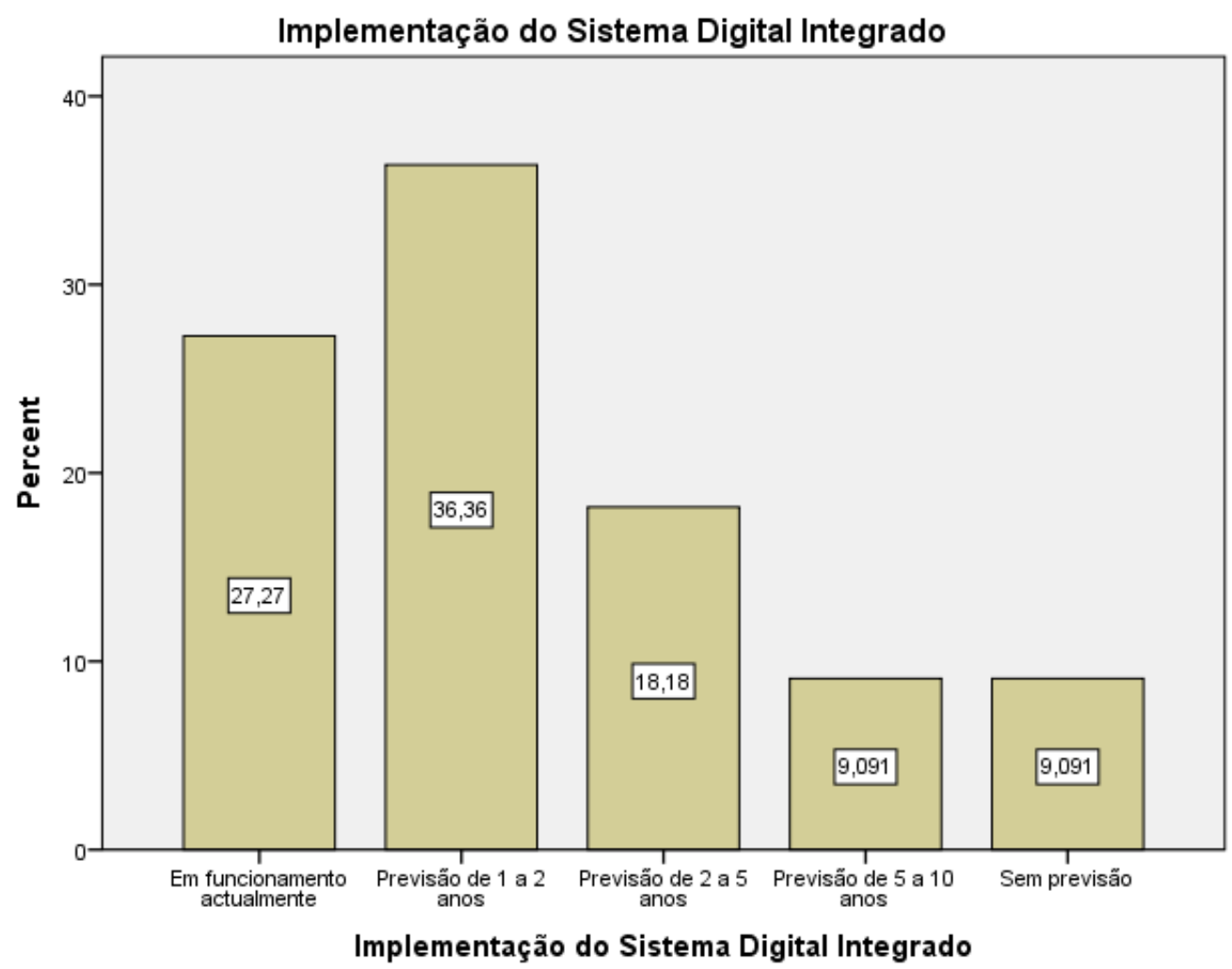

Gráfico 15 - Previsão da implementação do Sistema Digital integrado

\section{Considerações finais}

De acordo com as respostas dadas, observamos que as Instituições de maior dimensão são aquelas que dispõem de condições técnicas e humanas na gestão e preservação da informação.

No setor dos órgãos de comunicação, excetuando-se a rádio pública (RDP-RTP), a maioria não possuem um serviço de arquivo estruturado.

Praticamente, o único procedimento instituído na maioria das organizações inquiridas é relativo à conservação do espólio documental, não subsistindo um processo específico de tratamento e restauro dos documentos.

Relativamente às entidades públicas, estas são oriundas de museus e de bibliotecas, armazenando registos audiovisuais onde constam na maioria das situações, acontecimentos de história local.

Uma parte significativa dos documentos que se encontra nestas Instituições está registada em suporte sonoro e fotográfico e remonta ao início do século XX.

A Cinemateca, instituição que alberga o repositório do acervo fílmico nacional, é praticamente a única instituição que alberga diversos suportes em filme. 
De fato, observamos que a referida Instituição reúne as condições ideais para a preservação e tratamento técnico documental, dispondo de condições e meios técnicos e humanos, devido a esta ainda usufruir de apoio estatal.

Para a natureza em questão, o mesmo apoio deverá ser insuficiente, mas também constitui um único exemplo da como é instituída uma verdadeira politica de preservação do espólio audiovisual.

No que concerne aos registos documentais em formato de vídeo, estes estão praticamente confinados aos Departamentos de arquivo e de documentação nas estações de televisão, em virtude destas disporem de meios técnicos para a sua preservação.

No plano institucional, somente a Videoteca Municipal de Lisboa alberga um espólio documental considerável assim como apresenta igualmente um serviço estruturado, com algumas condições técnicas e recursos humanos necessários para preservar e gerir a informação.

Outra observação é relativa às condições de tratamento e organização documental. Uma parte significativa dos serviços está contemplada com um programa informático de base de dados para gerir a informação já arquivada.

A maioria dos programas foi concebida de acordo com a realidade arquivística de cada Instituição. Contudo, só uma minoria de organizações usufruiu de um software específico para descrever e classificar a informação, não possuindo os meios necessários para o restauro e preservação dos documentos. Uma parte considerável das entidades inquiridas não está preparada para incorporar um novo paradigma assente na gestão e preservação da informação em formato digital, uma vez que não reúnem condições técnicas nem foi desenvolvido por estas um conjunto de procedimentos no sentido de preservar e tratar esse tipo de informação, excetuando o caso da RTP que contraria essa situação.

As organizações nacionais com arquivos audiovisuais se continuarem neste impasse, de falta de investimento na área, dificilmente conseguirão integrar-se na era digital.

A maior carência verificada refere-se à preservação dos documentos, não se verificando uma política sustentada na adoção de procedimentos para a salvaguarda da informação.

Os requisitos instituídos na maioria entidades para preservar os documentos são mínimos, visando apenas a sua custódia. Não subsiste uma preocupação em garantir as condições ambientais apropriadas para evitar a degradação do acervo, gerado essencialmente devido á de meios financeiros para o efeito.

Relativamente à metodologia implementada no tratamento e organização da informação, esta é adaptada à realidade funcional de cada entidade, não sendo transporto na íntegra os princípios e as normas arquivísticas $(\operatorname{ISAD}(G))$ e as regras de catalogação.

Será utópico afirmar que a não integração das normas de arquivo ou de biblioteconomia na descrição de registos audiovisuais poderá constituir a principal causa das limitações que condicionam o funcionamento destas Instituições. Essa deficiência é relativa á ausência de uma política concreta para o setor. Uma das razões é a inexistência de um organismo regulador na área ou contrariamente ao que se passa com o panorama dos arquivos dito tradicional, existindo a DGARQ (Direção Geral de Arquivos) que tem um papel orientador no apoio técnico aos arquivos distritais e municipais.

A razão apontada é falta de recursos humanos e financeiros, mas existem outras razões, tornando-se redundante apontar sempre as mesmas causas.

Um condicionalismo gritante é questão legal, a legislação atual não responde às necessidades de arquivo, o único instrumento legal é o código de direitos de autor e direitos conexos centrando-se o referido código na proteção dos direitos intelectuais e reprodução da obra.

O estado que os arquivos audiovisuais atingiram, à exceção de alguns casos, também se deve à falta de sensibilidade por parte dos seus responsáveis, muitos destes nem se quer têm uma formação adequada na área.

O senso comum de muitos dirigentes de organizações privadas é alcançar resultados imediatos mas, não compreendem que o sucesso de uma organização depende de um arquivo organizado e estruturado. ${ }^{8}$ 
O sistema de informação de qualquer Instituição estará articulado com o serviço de arquivo e, se este último apresentar deficiências de funcionamento afetará o próprio sistema de informação.

O arquivo, independentemente da sua natureza, constitui um elemento central no qual veicula e flui a informação na organização. Este reflete o ambiente organizacional da Instituição, sendo esta a ideia-chave que terá de ser interiorizada por muitos dos responsáveis destes serviços. ${ }^{9}$

O pendor financeiro é um fator essencial em concomitância com outras medidas cruciais para dotar uma unidade de arquivo com as condições essenciais de funcionamento.

Esse conjunto de medidas de ordem técnica passa por estabelecer um planeamento de trabalho aliado a um conjunto de disposições na organização intelectual e física da informação. Nessa conformidade, urge o delineamento de quatro pontos fundamentais assentes em conceção de um sistema de informação aliado á construção de um programa informático, criação de condições ambientais para a preservação da informação, transposição da metodologia normativa de arquivo na organização intelectual da informação (sendo esta adaptada à realidade de funcionamento da organização) e, criação de um plano de preservação atendendo às novas tenologias da informação.

O plano fundamento nestes quatro postulados abrange três componentes: técnica, metodológica e sociológica, constituindo assim três vetores que devem estar inerentes à realidade funcional da Instituição.

A mudança organizacional terá de atender aos condicionalismos endógenos e exógenos da Instituição, nomeadamente á sua natureza e ao conteúdo da documentação. $O$ intuito é potencializar a sua ação e o seu papel no contexto da organização e na sociedade onde se insere.

Não obstante, a aplicação do conjunto destas sinergias obriga a um reenquadramento dos recursos humanos, não implicando um aumento de custos financeiros. Por um lado, a informatização e conceção do sistema de informação e definição de um plano de preservação são elementos crucias na otimização do seu funcionamento.

A opção por um software de open source poderá constituir uma solução de redução de custos mas, a maioria destas aplicações estão desenvolvidas para descrever o conteúdo informativo do acervo documental.

Porém, todas as aplicações informáticas desenvolvidas nesse sentido, na descrição e gestão da informação, deverão obedecer aos princípios e normas arquivísticos, alargando-se à recuperação da informação, isto possibilitará a utilização e construção de programas em linguagem HTML e XML, utilizando os padrões definidos de outras linguagens de descrição e meta-informação em ambiente digital, ${ }^{10}$ como é o caso da Dublin-core utilizada na transposição da meta-informação para um formato XML.

No campo da preservação, o modelo de referência OAIS (Open Archival Information System), ${ }^{11}$ é um modelo conceptual que visa identificar os componentes funcionais que deverão fazer parte de um sistema de informação dedicado à preservação digital fundamentado na ISO Standard 14721:2003.

Neste último domínio, a complexidade de adoção de um planeamento estruturado de acordo com os requisitos focados, poderá ser um obstáculo para as pequenas organizações.

Não obstante, existem outras medidas no sentido de preservar a informação, assinalando-se a normalização da informação arquivada ${ }^{12}$ com a utilização do PDF para armazenamento dos registos, à exceção dos documentos sonoros.

Visando a salvaguarda da informação e do conteúdo intelectual dos documentos, reconverter a informação em suporte analógico para digital, adotando para o efeito a migração de dados, constituindo a estratégia convencional mais utilizada.

Outro aspeto a considerar é a sensibilização para as questões ambientais e de segurança, essenciais na salvaguarda e manutenção do acervo documental em condições mínimas, podendo a aquisição do equipamento e instalações ser oneroso mas para a preconização de algumas medidas basta apenas existir vontade própria por parte do responsável pela gestão do arquivo. 
O conjunto de mudanças proposto exige recursos humanos especializados, uma forma de atenuar o aumento consubstanciado de custos financeiros, passa obrigatoriamente pelo estabelecimento de convenções entre as organizações e o meio académico, ou seja, com Instituições de ensino superior que disponham de cursos em Ciências da Informação.

O contributo de docentes e de alunos poderá ser um contributo precioso, no que concerne á implementação de novos projetos no sentido de modernizar e dinamizar os referidos arquivos.

Com o elevado desemprego, as Instituições Públicas e Privadas poderão recorrer a estagiários-licenciados na área das Ciências da Informação, estes poderão ser uma mais-valia para alterar o rumo dos acontecimentos.

É verdade que as Ciências da Informação estão ainda muito direcionadas para as Bibliotecas e Arquivos convencionais, descurando muitas vezes as Instituições que albergam espólio documental audiovisual. Porém, não nos podemos esquecer que estas últimas Instituições representam um papel importante na difusão e salvaguarda da informação, sendo um dos principais repositórios documentais do período contemporâneo.

Nesta perspetiva é fundamental uma mudança de mentalidade por parte dos agentes envolvidos na área, para que sejam instituídas medidas no sentido de alterar a situação de esquecimento que atinge as mesmas. Não obstante 0 caminho a percorrer na área dos arquivos audiovisuais em Portugal, que é imenso, para que estas entidades possam ter um papel ativo como agentes de informação e culturais. 


\section{Referências}

Birgit, Kofler (1991) Legal Questions facing Audiovisual Archives, Paris, General Information Programme and Unisist - UNESCO. Disponível em: < http://unesdoc.unesco.org/images/0008/000886/088674E.pdf >. Acesso: 15 Julho de 2012

Borbinha, José Luís et al (2002) Manifesto para a Preservação Digital, Lisboa, Cadernos Bad.

Consultative committee for Space data Systems (2012)- Reference More for an Open Archival Information System (OAIS), Recommended Practice - The Consultative Committee for Space Data Systems. Disponível em: $<$ public.ccsds.org/publications/RefModel.aspx> Pesquisado a 2 de Setembro de 2012.

Coordinating Council of Audiovisual Archive Association (2005) - UNESCO Instrument For THE Safeguarding And Preservation Of The Audiovisual Heritage - CCAAA ISSUES PAPER - UNESCO. Disponível em: $<$ http://www.ccaaa.org/docs/ccaaa heritage.pdf >

Chen, Su-Shing (2001)- The Paradox of Digital Preservation - Perspectives. Disponível em: $<$ http://www.fpdigital.com/resource/files/paradoxofdigitalpreservation.pdf >. Pesquisado a 2 de Setembro de 2012.

Chun, Wei Choo (2003)- Gestão de Informação para a Organização Inteligente, arte de explorar o meio ambiente, Lisboa. Editorial Caminho

Edmonson, Ray (1998)-Filosofia de Arquivos Audiovisuais, Paris, General Information Programme and Unisist - UNESCO. Disponível em: < http://es.scribd.com/doc/72771661/Uma-Filosofia-de-Arquivos-Audiovisuais> Pesquisado a 22 de Agosto 2012.

Fleischauer, Carl (2010)- Format Considerations in Audio- Visual Preservation Reformatting: Snapshots from the Federal Agencies Digitalization Guidelines Initiative - Information Standards Quarterly Vol.22. Disponível em: $<$ http://www.digitizationguidelines.gov/audio-visual/documents/IP Fleischhauer AudioVisual Reformatting isqv22no2.pdf>. Acesso a 22 de Agosto 2012.

International Association of Sound Audiovisual Archives (IASA) TC (2005) La salvaguarda del Patrimonio sonoro: Etica, Principios y Estratégia de Preservación; International Association of Sound and Audiovisual Archives - IASA.

Harrison, Helen P (1997) -Audiovisual Archives Pratice Reader, Paris. General Information Programme and Unisist - UNESCO Disponível em: < http://unesdoc.unesco.org/images/0010/001096/109612EO.pdf > Acesso a 21 de Agosto de 2012.

Pinto; Maria Manuela Gomes (2009-) Gestão da informação e preservação digital: uma perspetiva portuguesa de mudança de paradigma, Valencia - Congreso Iska Espanã. Disponível em:

< http://repositorio-aberto.up.pt/bitstream/10216/25380/2/manuelapintogestao000100395.pdf > Acesso a 19 de Julho de 2012.

Rádio Televisão Portuguesa (1996)- Guia dos Arquivos Audiovisuais em Portugal, Incluindo as coleções fotográficas e sonoras mais significativas. Lisboa TV Guia Editora. 


\section{Dados do autor}

Nuno Miguel Epifânio

Possui a Graduação em História concluída na Faculdade de Letras na Universidade de Coimbra (2004), Pós-

Graduado em Arquivos e Bibliotecas e Ciências da Informação (2007) e Mestre em Ciências da Informação pela Universidade de Évora (2010). Atualmente, frequenta o programa de estudos avançados, curso de doutorado, em Ciências da Informação da Universidade de Évora. Desempenhou as funções de Técnico Superior de Arquivo na Administração Local em Portugal (2007-2011).

nupifanio@live.com.pt

Recebido - Received: 2012-12-19

Aceitado - Accepted: 2012-12-30

\section{(c) EY New articles in this journal are licensed under a Creative Commons Attribution 3.0} United States License.

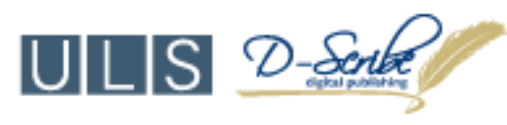

This journal is published by the University Library System of the University of Pittsburgh as part of its D-Scribe Digital Publishing Program and is cosponsored by the University of Pittsburgh Press. 


\section{Biblios}

Statistical interpretation of the process of evolution ...

\section{NOTAS}

1 - C.F- FIAF-Fédération Internationale des Archives du Film

2 - C.F- IASA. International Association of Sound and Audiovisual Archives.

3 - C.F (Edmonson, Ray, 1998, p.15) - "Há dois aspetos chave: primeiro, um arquivo audiovisual é uma organização não é uma coleção privada a cargo de um indivíduo. Segundo, o conjunto colecionar/administrar/preservar/fornecer acesso a documentos audiovisuais é seu principal objetivo, não só uma atividade acessória entre outras".

4 - C.F. (Harrison, Helen, 1997, p.1) - "Archives exist for the preservation and continuation of the cultural heritage and that heritage is made from a variety of cultures, past and current civilizations, artefacts, manuscripts and printed materials and the more recent phenomena of audiovisual materials and electronic documents".

5 . Rádio Televisão Portuguesa, (1996) - Guia dos Arquivos Audiovisuais em Portugal: incluindo as coleções fotográficas mais significativas. Lisboa: TV Guia Editora.

, 6 CF- (Birgit, Koffler, 1991, p.4). "In most countries, there is no comprehensive legislation on audiovisual archiving as such, juridical answers to the questions guiding our research are contained in different bodies of law, from general archive legislation to film legislation, from copyright provisions to import and export rules, from legislation on the protection of cultural heritage to deposit and censorship regulations".

7 De referir que, por imposição do software usado - SPSS -, as percentagens apresentadas são as percentagens válidas (depois de retirado dos cálculos os registos inválidos, sendo que a soma das percentagens pode em certos casos exceder os $100 \%$.

8 -CF- (Choo, Chun Wei, 2003, p. 288) "Cada organização precisa de desenvolver o seu próprio sistema de exploração personalizado que se ocupe das suas aspirações, do seu posicionamento.

9 - CF- (Harrison, Helen, 1997, p.14)- "An AV archive is an organization or department of an organization which is focused on collecting, managing, preserving and providing access to a collection of AV media and the AV heritage".

10 C.F- (Shen, Shu-Shing, 2001, p.4) -"We need policies and automatic tools to translate those policies into metadata decisions. For each preserved record, metadata represents

the following: standards, languages, data structures, linkages to logically or physically remote

ancillaries, presenters and interpreters, software, terminology"

11 C.F. (CCSDS, 2012, p.2) - "The OAIS model in this document may be applicable to any Archive. It is specifically applicable to organizations with the responsibility of making information available for the Long Term. This includes organizations with other responsibilities, such as processing and distribution in response to programmatic needs".

12 C.F (Borbinha, José Luis et al, 2002, p.72) - No caso dos arquivos audiovisuais, além das estratégias necessárias à preservação dos novos conteúdos, em grande parte já criados em meios e formatos digitais, é ainda de realçar o potencial que a digitalização pode representar para os meios analógicos tradicionais. Um documento audiovisual necessita sempre de um suporte (por exemplo, filme e cassetes), e mesmo nas condições de arquivo ótimas, (respeitando níveis de temperatura, humidade, e exposição à luz) estes suportes estão sempre sujeitos a um estado natural de degradação contínua com o tempo, a qual pode chegar a um ponto que torne o restauro impraticável 